\section{REGENERACIÓN URBANA Y GESTIÓN DEL RIESGO EN CHILE: ANÁLISIS COMPARATIVO DE CASOS}

Juan Pablo Sarmiento Prieto ${ }^{1}$, Antonio Fritis Estay $^{2}$, Carmen Paz Castro Correa ${ }^{3}$

\section{Resumen}

El estudio analiza siete casos de regeneración urbana que incorporan medidas de gestión del riesgo en barrios expuestos a riesgos socionaturales. El artículo comienza con una introducción a los temas de regeneración urbana y gestión del riesgo, para luego enfocarse en el desempeño del programa de regeneración urbana "Quiero Mi Barrio" (PQMB) del Ministerio de Vivienda y Urbanismo de Chile. Aplicando un análisis comparativo de casos de estudio a siete experiencias del PQMB, el artículo muestra que es posible transversalizar medidas de reducción de riesgos en el diseño de obras

\section{URBAN REGENERATION AND RISK MANAGEMENT IN CHILE: COMPARATIVE CASE STUDY ANALYSIS}

\author{
Juan Pablo Sarmiento Prieto, Antonio Fritis \\ Estay, Carmen Paz Castro Correa
}

\section{Abstract}

This study analyses seven urban regeneration cases, which incorporate risk management measures, in neighborhoods exposed to socionatural risks. The article begins with an introduction to the urban regeneration and risk management topics, to then focus on the performance of Chile's Ministry of Housing urban regeneration program "Quiero Mi Barrio" (PQMB). Applying a comparative case study analysis method to the seven $P Q M B$ experiences, the article shows that it is possible to mainstream risk reduction measures into the design of infrastructure works and in social interventions 
de infraestructura e intervenciones sociales dentro de las operaciones de regeneración urbana, concluyendo que la experiencia del $\mathrm{PQMB}$ ha contribuido efectiva y eficientemente a la seguridad del barrio y su comunidad. Por otra parte, a través de dichas medidas, el $\mathrm{PQMB}$ ha promovido el fortalecimiento de la participación ciudadana y los procesos de gobernanza a niveles nacionales, regionales, locales y comunitarios. El análisis llevado a cabo, los procesos utilizados y los resultados obtenidos por el PQMB permiten informar decisiones tanto en investigación como en regeneración urbana y gestión del riesgo de desastres.

PALABRAS ClaVE: PROGRAMA QUIERO MI BARRIO, REGENERACIÓN URBANA, REDUCCIÓN DEL RIESGO DE DESASTRES, GOBERNANZA, COMUNIDAD.

Recibido: 2020-03-10

Aceptado: 2020-09-07

$1 \quad$ Director asociado de investigación en el Instituto de Eventos Extremos de Florida International University, Estados Unidos, http://orcid.org/0000-0001-8192-902X. jsarmien@fiu. edu

2 Encargado Nacional Área Urbana Programa Recuperación de Barrios en Ministerio de Vivienda y Urbanismo de Chile MINVU, Chile, http://orcid.org/0000-0001-8544-2825. Correo electrónico: afritis@minvu.cl within urban regeneration operations, and concludes that the experience of the PQMB has contributed effectively and efficiently to the security of the neighborhood and its community. On the other hand, through these measures, the $P Q M B$ has contributed to strengthen citizen participation and governance processes at the national, regional, local, and community levels. The analysis carried out, the processes used, and the results obtained by the PQMB, allow to inform decisions in research, as well as in urban regeneration and disaster risk management.

\section{KEYWORDS: QUIERO MI BARRIO PROGRAM, URBAN REGENERATION, DISASTER RISK REDUCTION, GOVERNANCE, COMMUNITY.}

Received: 2020-03-10

Accepted: 2020-09-07 


\section{Introducción}

Los orígenes del movimiento regeneración urbana se ubican en el Reino Unido a inicios de la década de 1990, extendiéndose rápidamente a otros países europeos (Roberts, 2000; Smith, 2011). Sin embargo, es importante indicar que la regeneración urbana surge en Europa mucho antes, como resultado de un proceso iniciado hace más de 40 años con la reconstrucción de posguerra en la década de 1950, seguida de la política de revitalización de los 60 (como reacción a la caída de las economías locales) la cual a antecedió a la política de renovación de barrios de los 70 y a las tendencias desarrollistas de los 80. La visión de regeneración de los 90 se nutrió de estas políticas que la precedieron, buscando asociar integralmente política y práctica en intervenciones urbanas (Bewick y Tsenkova, 2002). Esta asociación con periodos anteriores fue abordada inicialmente por Coach (1990), quién indicó que la regeneración urbana se diferencia de la revitalización (o rehabilitación) ya que esta última se limita a un método de enfoque único y rígido, trascendiendo la renovación urbana -considerada como un proceso de cambio esencialmente físicoy yendo más allá del desarrollo urbano (o reurbanización), pues éste tiene una misión y un propósito demasiado generales.

Según Roberts (2000) la regeneración urbana es una visión y una acción integral que conduce a la resolución de problemas urbanos y que busca lograr una mejora duradera en las condiciones físicas, sociales, económicas y ambientales de un área o territorio que ha estado sujeta a cambios. Para Roberts, la regeneración urbana corresponde a un propósito estratégico a largo plazo que exige de una integración intersectorial.

Como parte del telón de fondo a todo este proceso de transición de políticas urbanas, es necesario hablar del neoliberalismo como un modelo prevalente a nivel global que también se expresa en lo urbano. Mayer (2007) hace referencia a las «ciudades neoliberales» que se conciben bajo políticas favorables al crecimiento económico y al desmantelamiento del estado de bienestar y de la justicia social y ambiental, en favor de incentivos a la empresarialidad, la privatización de servicios, la desregulación del uso de la tierra, y la construcción de megaproyectos atractivos para la inversión. Los resultados saltan a la vista: mayor autonomía municipal con exiguos presupuestos, crecimiento de los mercados formales e informales de la tierra y la vivienda, deterioro de los barrios de vivienda popular y disminución de las inversiones sociales. Paralelamente, aparecen discursos sobre el deterioro urbano y la necesidad de abordarlo a través de una renovación, con el consecuente efecto: gentrificación. Como dice Mayer, «la neoliberalización de la ciudad ha creado de muchas maneras un entorno más hostil y más difícil para el progreso de los movimientos urbanos» (Mayer, 2009, p. 367). 
Si bien los inicios de la regeneración urbana se asocian a un evento antrópico destructivo de gran envergadura -la segunda guerra mundial-, podríamos afirmar que no existe un marco conceptual específico referido a la regeneración urbana y el abordaje del riesgo de desastre, circunstancia que aborda este estudio. A través del tiempo, sectores urbanos con deterioro físico han demostrado que, además de los riesgos propios de edificaciones vetustas y en mal estado (colapsos, incendios, problemas sanitarios), están frecuentemente expuestos a riesgos socionaturales (sismos, inundaciones, deslizamientos). La regeneración urbana se ha visto abocada a responder al impacto de eventos adversos como los antes mencionados, actuando reactivamente en procesos de reconstrucción post-desastre. Por otra parte, en la medida en que ha avanzado el conocimiento y el interés por el tema del riesgo de desastres a nivel mundial, la regeneración urbana ha tenido que integrarla en sus operaciones en forma proactiva (actuando en ambientes construidos y en deterioro antes que el riesgo se transforme en desastre), a través de medidas físicas, como reforzamiento estructural, muros de contención y reubicaciones parciales o totales, entre otras acciones. Cualesquiera sean estas intervenciones físicas reactivas o proactivas, necesitan gestiones de carácter social que ayuden a reducir aquellos factores no estructurales del riesgo representados por la vulnerabilidad social, cultural y económica (Güzey, 2016).

A comienzos del siglo XXI, en el auge de las políticas neoliberales urbanas, surge en Chile el programa "Quiero Mi Barrio" (PQMB) del Ministerio de Vivienda y Urbanismo (MINVU) para enfrentar el problema de deterioro de la infraestructura urbana en los barrios de vivienda popular (Ministerio de Vivienda y Urbanismo [MINVU], s.f.). El programa nace en 2006 y basa su trabajo en las interacciones con la comunidad, el municipio y equipos barriales especializados, buscando facilitar el encuentro, la participación y la vida barrial mediante la recuperación física y social, a partir de un diagnóstico integral que fortalece el vínculo del barrio con la comunidad.

A través de los años, el desarrollo del PQMB ha tenido que hacer frente a una serie de eventos de desastres en el territorio nacional, ya sea porque estos han generado un impacto en los proyectos de regeneración urbana en curso, o bien porque a raíz de un desastre el PQMB se ha involucrado contribuyendo a los procesos de recuperación de las comunidades afectadas. Desde el 2014, el PQMB inició la incorporación del enfoque de reducción del riesgo de desastres de forma proactiva y prospectiva (antes de que suceda un evento desastroso) en su metodología de trabajo. 
El presente estudio analiza los resultados de siete experiencias de este programa de regeneración urbana en Chile, casos que se generaron como procesos de rehabilitación y reconstrucción post desastre.

\section{Métodos}

La investigación realizada incluyó una revisión de la literatura y un análisis de desempeño del PQMB en relación con el tema de gestión de riesgos, para luego emplear la metodología de análisis comparativo de casos en siete experiencias del PQMB.

La revisión de la literatura abarcó una búsqueda de publicaciones académicas con relación al origen, evolución y tendencias de la teoría de regeneración urbana, enfocada a la gestión de riesgos de desastres y con referencia a experiencias en Latinoamérica.

La metodología de análisis comparativo de casos sigue las orientaciones propuestas por Goodrick (2014) y Hart (2018), que consideran los estudios de caso comparativos como "el análisis y la síntesis de las similitudes, diferencias y patrones de dos o más casos que comparten un enfoque o meta común" Goodrick (2014, p. 3). Esta aproximación demanda una apropiada profundidad en el conocimiento de las características y contextos específicos de cada caso, en correspondencia al marco teórico que se expone en esta sección. Se emplearon diversos métodos de recolección de datos, incluyendo visitas sobre el terreno, observación, instrumentos de evaluación y el análisis documental.

La característica más relevante de los estudios de caso comparativos y la razón por la cual se eligió esta aproximación es el interés en analizar la medida en que la intervención realizada generó los resultados e impactos esperados (Robinson, 2016). Esta característica de causalidad es la que permite ubicar esta aproximación dentro de la investigación basada en evidencia (IBE), construida sobre un análisis sistemático, en este caso, del desempeño del PQMB, a través del análisis de intervenciones reales llevadas a cabo durante la vida del programa.

Con el fin de optimizar el uso del método de análisis comparativo de casos, este estudio incluyó en su diseño una adaptación de las cinco preguntas propuestas por Krehl y Weck (2019), por considerarlas de especial pertinencia:

- ¿Cuál es el marco teórico del estudio?

- ¿Se busca teorizar, generalizar, o comprobar una hipótesis?

- ¿Cómo se han elegido los casos?

- Dentro de cada caso, ¿qué constituye el caso, es decir, el objetivo de la comparación?

- ¿Qué compensaciones (trade-offs) ocurrieron? 


\section{MARCO TEÓRICO}

El marco teórico de este estudio se construye a partir de la propuesta de sistema de Tsenkova (2002), pero con ajustes que permitan comprender la problemática urbana sobre la cual actúa la propuesta de regeneración, dentro de un contexto de riesgo de desastre. La figura 1 ilustra posibles factores de cambio negativos involucrados en los cambios experimentados a nivel de un territorio en particular, pudiendo ser estos un resultado de tendencias económicas (neoliberalismo), sociales (movilidad social) o espaciales (abandono de centros urbanos, preferencia por periferias), o bien, consecuencia de cambios a nivel de la gobernanza local (interacción gobierno local, sociedad civil y comunidad), la tecnología (mercados y banca online), y las políticas nacionales (regulación urbano-rural, incentivos al sector de la construcción). Otros aspectos que pueden influir en el territorio son: las amenazas, las cuales pueden tener un carácter potencial (naturales, socionaturales o antrópicas), o bien, ya materializado en situaciones de emergencia o de desastre con el respectivo impacto (directo e indirecto); $y$, por otro lado, los efectos secundarios evidentes en los grandes agregados macroeconómicos como inflación, crecimiento económico, desequilibrios en la balanza de pagos e incremento del gasto público.
En el centro de la Figura 1 se encuentra la comunidad analizada ubicada en una unidad territorial específica, la cual se caracteriza a través de tres esferas: la social (incluye el análisis de recursos humanos, estatus socioeconómico, deprivación social, exclusión, segmentación), la económica (contempla los medios de vida, estructura de la economía local, desempleo, vínculos económicos) y la física (abarca la calidad de la vivienda, las condiciones del tejido urbano, calidad del equipamiento urbano, condiciones de saneamiento ambiental).

El modelo de factores de cambio expuesto ofrece el escenario en el cual interactúa la propuesta de regeneración urbana, particularmente en el programa de regeneración del PQMB del MINVU de Chile, cuyos resultados se detallan en la siguiente sección de este artículo.

\section{HIPÓTESIS DEL ESTUDIO}

La hipótesis que subyace a este estudio propone que los procesos de intervención social y física de regeneración urbana del $\mathrm{PQMB}$ que cuentan con un enfoque transversal de gestión de riesgos están en mejores condiciones para enfrentar problemas de exposición a riesgos socionaturales y para adelantar procesos de recuperación pos-evento. 
FIGURA 1. MODELO FACTORES DE CAMBIO INVOLUCRADOS EN LA PRECARIEDAD E INFORMALIDAD.

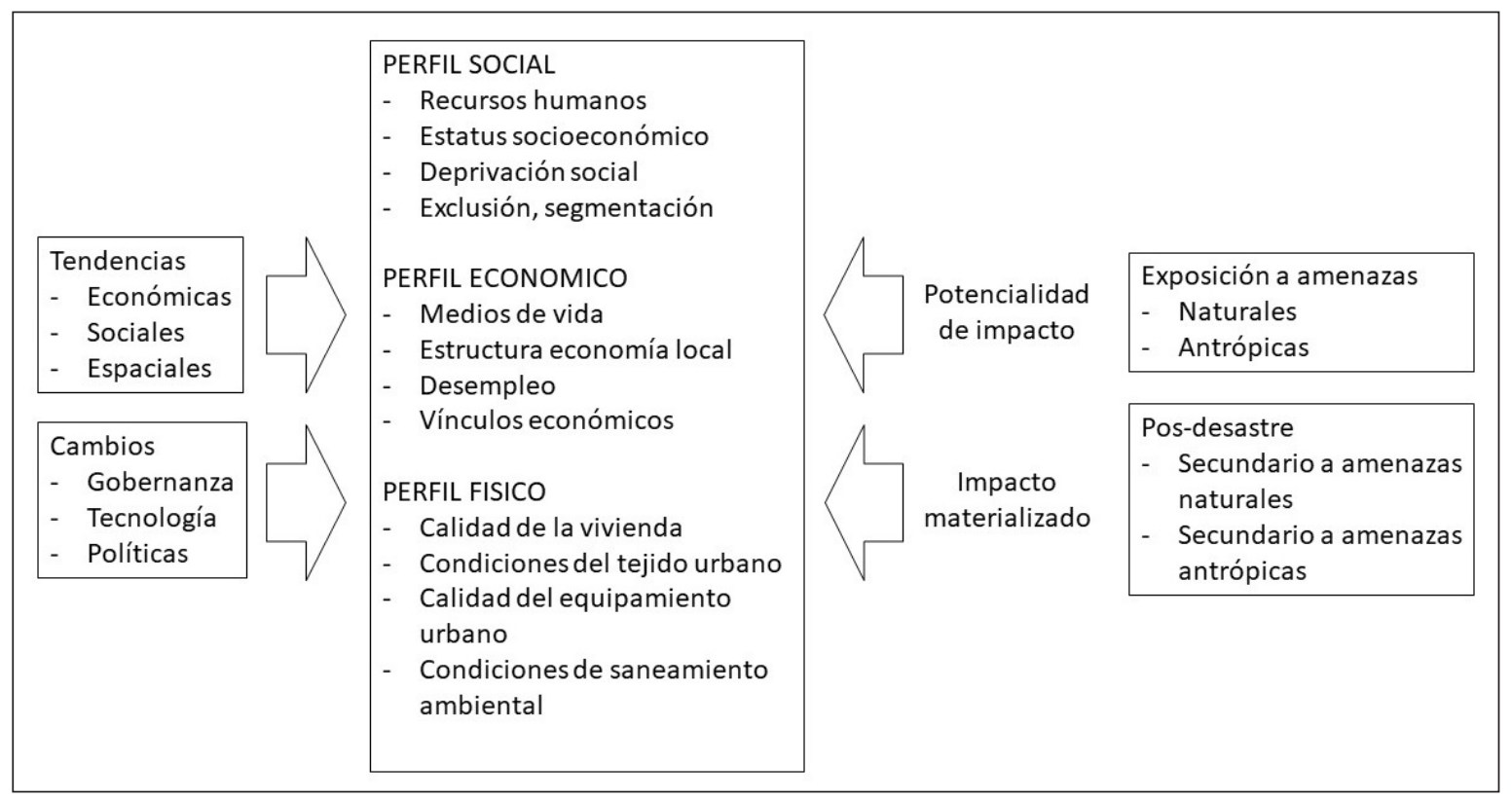

Fuente: Elaboración a partir del modelo propuesto por Tsenkova, 2002.

Los elementos clave de esta hipótesis son:

- Unidad de análisis: Los procesos de intervención social y física de regeneración urbana del PQMB.

- Variables a considerar: uso del enfoque transversal de gestión de riesgos, evaluación del riesgo previa y posterior al programa, intervenciones sociales y físicas de regeneración urbana que integran la reducción riesgos.
- Elementos lógicos: contar con un enfoque transversal ofrece mejores para enfrentar riesgos y eventos.

Esta hipótesis abarca el PQMB en su accionar en gestión de riesgos y en cierta manera trasciende el alcance de este estudio; sin embargo, al estar éste basado en un análisis cualitativo de siete estudios de caso, orienta el propósito y la selección de la información a considerar en el análisis comparativo de casos (Krehl y Weck, 2019). 


\section{SELECCIÓN DE CASOS}

Aun cuando el PQMB ha adelantado en su historia múltiples intervenciones físicas y sociales asociadas al tema de gestión de riesgos, se procedió a identificar aquellos barrios en donde la regeneración urbana había sido culminada, y que hubieran incluido explícitamente en su diseño la gestión del riesgo de desastre como un componente transversal.

\section{ALCANCE DE LA COMPARACIÓN}

Interesa analizar los procesos empleados por el PQMB en cada caso y, como se mencionó, la medida en que la intervención generó los resultados e impactos esperados. Se adelantará una caracterización general de cada caso, incluyendo la evaluación del riesgo (previa $\mathrm{y}$ posterior al programa) las intervenciones sociales y físicas de regeneración urbana que integran la reducción riesgos y el presupuesto.

\section{COMPENSACIONES (TRADE-OFFS)}

Uno de los retos que surge del estudio consiste en la estimación de las inversiones realizadas por barrio. En los siete casos estudiados, como en todos los barrios del PQMB, existe un techo presupuestal regular dispuesto al momento de entrar a concurso, postulado por los municipios. Quiere esto decir que, en el caso de barrios impactados por desastres socionaturales o acciones prospectivas para barrios donde hay exposición a riesgos sin incremento en el presupuesto, se integra transversalmente el concepto y enfoque de reducción del riesgo de desastres.

A pesar de no contar con una nueva reglamentación en el MINVU que otorgara al PQMB el reconocimiento y los medios necesarios para integrar la temática del riesgo de desastre como tercera causal de intervención del programa, el PQMB, ha logrado aprovechar ventanas de oportunidad enmarcadas en el Plan Estratégico Nacional para la Gestión del Riesgo de Desastres 2015-2018 (Oficina Nacional de Emergencia del Ministerio del Interior, 2016) para beneficiarse de recursos adicionales de otras fuentes de financiación, lo cual le ha permitido una mayor inversión en el tema de riesgos. A principios de septiembre 2020, el MINVU emitió un lineamiento a nivel nacional para la aplicación del Índice de Gestión de Riesgos IGR en todos los barrios que entren al programa a partir de esta fecha. Este IGR se describe más adelante en mayor detalle.

\section{Resultados y discusión}

En esta sección se incluye una mención a las tendencias recientes de la regeneración urbana, así como la necesaria y válida asociación con la gestión de riesgos de desastres y las referencias a experiencias en Latinoamérica. Posteriormente se analiza el desempeño del PQMB con relación a la gestión del riesgo. 
La regeneración urbana reconoce la imperiosa necesidad de integrar las políticas de transformación física y económica con las políticas sociales y ambientales, esenciales para conseguir una revitalización urbana con enfoque integral (Coach, 1999). Como toda teoría, hay algunos principios de la regeneración urbana que marcan una clara diferencia con otros enfoques:

- Basarse en un análisis de las condiciones locales, comprendiendo lo local como correspondiente a una unidad territorial en particular, usualmente equivalente a un municipio o intendencia.

- Establecer objetivosclarosycuantificados.

- Enfocar un cambio integral en el tejido físico, estructuras sociales, base económica y condiciones ambientales.

- Ser coherente con los objetivos del desarrollo sostenible.

- Hacer el mejor uso posible de los recursos naturales, económicos, humanos y otros disponibles.

- Buscar la participación y el consenso entre las partes interesadas.

- Medir el progreso de la estrategia y supervisar las fuerzas internas y externas cambiantes que actúan en las áreas locales.

- Reconocer que diferentes elementos de la estrategia progresarán a diferentes velocidades.

Indudablemente, en los temas de regeneración urbana hay un componente que busca el abordaje de una degradación física asociada a aspectos de deterioro social, económico y ambiental, circunstancias que han hecho que ciudades alrededor del mundo, particularmente en países desarrollados, hayan tenido que reinventarse. Otro tema de interés, compartido por ciudades europeas, norteamericanas y de algunos países que ingresan más recientemente al grupo del mundo industrializado, es el de la inmigración. Así, y de manera mucho más concreta en el continente americano, también ha ido creciendo la comprensión y el interés por profundizar la dinámica entre desastres socionaturales y cambio climático con las distintas formas de movilidad humana, incluyendo las áreas de expulsión como de las zonas de recepción o acogida. Estas últimas coinciden frecuentemente con procesos en curso de deterioro físico y social urbano, lo que ha complicado significativamente en las últimas décadas el abordaje de la problemática desde la gestión urbana y la gestión del riesgo (Sarmiento, Castro-Correa, Sandoval, y Hoberman, 2020).

Para Latinoamérica hay un factor de gran importancia que no es mencionado explícitamente en la literatura revisada sobre el tema de regeneración urbana: las amenazas naturales y antrópicas. Sin embargo, es importante mencionar que hay referencias como la Declaración de Toledo de la UE (Presidencia Española, 2010), en las que el cambio climático o ciertas acciones humanas 
-como la contaminación en ambientes urbanosson consideradas como grandes desafíos que debieran ser abordados a través de la regeneración urbana. Por otra parte, no hay que olvidar que el riesgo de desastre se considera una construcción social, por lo que el ambiente construido es, en última instancia, un aporte del ser humano a la construcción del riesgo, estando este así indudablemente ligado a los procesos de urbanización.

\section{EL PROGRAMA OUIERO MI BARRIO}

El programa "Quiero Mi Barrio" nace el año 2006, como política pública de regeneración urbana con un tipo de gestión territorial articulado bajo un modelo de intervención donde interactúan gobiernos regionales, locales y la ciudadanía, mediante un modelo de urbanismo ciudadano caracterizado por la coproducción participativa a lo largo de todo el proceso de diagnóstico, diseño y ejecución de proyectos físico-sociales, estableciendo acuerdos de convivencia entre las partes. A la fecha de inicio de este estudio, el PQMB había seleccionado 570 barrios en todo el país, y para finales del 2017, un total de 348 se encontraban terminados.

La inversión por barrio es cercana a los 497 millones de pesos (US\$605.000), dividiéndose en planes de gestión de obras y social, 395 (US\$481.000) y 102 millones (US\$124.000) respectivamente.
Debido al impacto generado por desastres socionaturales en el territorio chileno, el PQMB decidió en los últimos cinco años abordar funcionalmente el tema de gestión de riesgos. En este contexto, se adoptaron cinco conceptos, promovidos por la oficina de Naciones Unidas, que promueven la gestión de riesgos UNRRD:

"Amenaza: Proceso, fenómeno o actividad humana que puede ocasionar muertes, lesiones u otros efectos en la salud, daños a los bienes, disrupciones sociales y económicas o daños ambientales.'

"Exposición: Situación en que se encuentran las personas, las infraestructuras, las viviendas, las capacidades de producción y otros activos humanos tangibles situados en zonas expuestas a amenazas."

"Vulnerabilidad: Condiciones determinadas por factores o procesos físicos, sociales, económicos y ambientales que aumentan la susceptibilidad de una persona, de una comunidad, de sus bienes o de los sistemas a los efectos de las amenazas."

"Riesgo de desastres: Posibilidad de que se produzcan muertes, lesiones o destrucción y daños en bienes en un sistema, una sociedad o una comunidad en un período de tiempo concreto, determinada de forma probabilística como función de la amenaza, la exposición, la vulnerabilidad y la capacidad."

"Gestión del Riesgo: Aplicación de políticas y estrategias de reducción del riesgo de desastres con el propósito de prevenir nuevos riesgos de desastres, reducir los riesgos de los desastres existentes y gestionar el riesgo residual, 
contribuyendo con ello al fortalecimiento de la resiliencia y a la reducción de las pérdidas por desastres" ("Informe del grupo de trabajo", 2016, pp. 15-25).

La decisión del PQMB de integrar el tema de gestión de riesgos se traduce en diagnósticos territoriales participativos en que se reconocen amenazas, vulnerabilidades y capacidades del territorio, con el fin de construir un plan maestro para cada barrio, de carácter indicativo, que contribuya a la mitigación del riesgo, a la definición de vías de evacuación y zonas seguras, así como a la definición de un plan de acción comunitario dentro de cada barrio, destinado a mejorar la calidad de vida y fortalecer la resiliencia.

En el período comprendido entre los años 2006 y 2016, diversos eventos geológicos e hidrometeorológicos afectaron varias zonas del país, y como parte de la reconstrucción de estos territorios, el PQMB se hace presente con el fin de acompañar a la población en este proceso y también como una forma de contribución al mejoramiento de áreas deterioradas de la ciudad, y como una medida de rehabilitación urbana y de reducción del riesgo de desastre.

La Tabla 1 recoge algunas experiencias significativas en desastres del PQMB. Como puede observarse en la columna de acción del
PQMB, en algunos casos el programa estaba presente antes del evento, mientras que en otros fue llamado a intervenir.

Un análisis más exhaustivo permitió identificar un total de 33 proyectos (6.35\%) para barrios afectados severamente por eventos naturales. De estos 33 proyectos, cuatro fueron seleccionados como piloto para incluir transversalmente la gestión de riesgos, incluyendo luego a 14 proyectos más, que cuentan con una comisión de reducción de riesgos.

\section{SELECCIÓN DE LOS CASOS DE ESTUDIO}

Siguiendo los criterios de inclusión descritos en la metodología, del universo de 520 barrios del PQMB distribuidos a lo largo del país, se procedió a identificar aquellos de regeneración urbana que 1) hubieran incluido explícitamente en su diseño la gestión de riesgo de desastre como un componente transversal y 2) hubieran formalmente culminado.

Siete barrios del PQMB cumplieron con los dos criterios de inclusión. Tres de ellos expuestos a la amenaza de terremotos y tsunamis (Regiones de Arica y Parinacota, y de Los Lagos) y cuatro a la amenaza de incendios forestales y de interfase (Región de Valparaíso). 


\begin{tabular}{|c|c|c|}
\hline Año & Evento & Acción PQMB \\
\hline 2007 & $\begin{array}{l}\text { Terremoto que afectó el Norte Grande del país } 7.7 \\
\text { Mw. }\end{array}$ & Reubicación comuna de Tocopilla \\
\hline 2010 & $\begin{array}{l}\text { Terremoto } 8.8 \text { Mw que afectó la zona centro sur del } \\
\text { país. } 802 \text { fallecidos, cerca de } 820.000 \text { damnificados } \\
\text { y cerca de } 400.000 \text { viviendas con daños de diversa } \\
\text { consideración. }\end{array}$ & $\begin{array}{l}\text { EI PQMB se incorpora decididamente el } \\
\text { proceso de reconstrucción }\end{array}$ \\
\hline 2014 & $\begin{array}{l}\text { Terremoto que afectó al país, pero en el extremo } \\
\text { norte, con una magnitud de } 8.2 \mathrm{Mw} \text {. }\end{array}$ & $\begin{array}{l}\text { Siete nuevos barrios de interés regional } \\
\text { como reconstrucción del POMB, ubicados } \\
\text { en las regiones de Arica y Parinacota y } \\
\text { Tarapacá. }\end{array}$ \\
\hline 2014 & $\begin{array}{l}\text { Incendios forestales con el mayor impacto de las } \\
\text { últimas décadas en el área urbana de Valparaíso. } \\
\text { Afectaron } 965 \text { hectáreas, de las cuales } 28,5 \\
\text { correspondieron a zonas habitadas. } 2.900 \text { viviendas } \\
\text { resultaron destruidas con } 12.000 \text { damnificados, } 15 \\
\text { fallecidos y } 500 \text { heridos. }\end{array}$ & $\begin{array}{l}\text { El PQMB incorpora cuatro nuevos barrios } \\
\text { localizados en los cerros de Valparaíso que } \\
\text { fueron completamente quemados. }\end{array}$ \\
\hline
\end{tabular}

201530.000 damnificados, 97.000 afectados y cerca de 20.000 viviendas con daños de diversa magnitud.

\section{Erupción del volcán Calbuco, en la región de Los}

2015 Lagos, y aluvión que afectaron la zona norte del país, específicamente la zona de Tocopilla

Terremoto 8.4 Mw que afectó la zona centro norte 2015 del país, con epicentro en Canela Baja. 15 fallecidos, 18.000 damnificados y 9.800 viviendas resultaron con daños de diversa consideración.

Incendio Forestal en el sector de Puertas Negras de 2017 Playa Ancha Valparaíso, que afectó a 250 viviendas, quedando 238 personas albergadas, 19 heridos.
El POMB incorpora dos nuevos en la región de Atacama.

EI PQMB tenía barrios en ejecución previo a los eventos.

Tres barrios del Programa fueron afectados por este evento.

EI PQMB incorpora un nuevo barrio localizado en el sector alto de Playa Ancha de Valparaíso que fue quemado en su parte periférica 
TABLA 2. CARACTERIZACIÓN DE LOS SIETE CASOS DE ESTUDIO DEL PROGRAMA QUIERO MI BARRIO

\begin{tabular}{|c|c|c|c|c|c|c|c|}
\hline $\begin{array}{l}\text { Barrio y año } \\
\text { de inicio }\end{array}$ & Región & Comuna & Riesgo & $\begin{array}{l}\text { Población \# } \\
\text { habitantes }\end{array}$ & $\begin{array}{l}\text { Densidad } \\
\text { hab./hec. }\end{array}$ & $\begin{array}{l}\text { Economía } \\
\text { predominante }\end{array}$ & $\begin{array}{l}\text { Inversión } \\
\text { PQMB }\end{array}$ \\
\hline $\begin{array}{l}\text { Barrio Jorge } \\
\text { Inostroza, } \\
2016\end{array}$ & $\begin{array}{l}\text { Arica y } \\
\text { Parinacota }\end{array}$ & Arica & $\begin{array}{l}\text { Terremoto y } \\
\text { Tsunami }\end{array}$ & 1563 & 85 & Comercio & $\begin{array}{l}\text { \$657.3 millones } \\
\text { USD } \$ 0.8 \\
\text { millones }\end{array}$ \\
\hline $\begin{array}{l}\text { Barrio Puerta } \\
\text { Norte, } 2016\end{array}$ & $\begin{array}{l}\text { Arica y } \\
\text { Parinacota }\end{array}$ & Arica & $\begin{array}{l}\text { Terremoto y } \\
\text { Tsunami }\end{array}$ & 1895 & 124 & $\begin{array}{l}\text { Servicios y } \\
\text { Comercio }\end{array}$ & $\begin{array}{l}\text { \$637.3 millones } \\
\text { USD } \$ 0.77 \\
\text { millones }\end{array}$ \\
\hline $\begin{array}{l}\text { Barrio Las } \\
\text { Cañas, } 2014\end{array}$ & Valparaíso & Valparaíso & $\begin{array}{l}\text { Incendios } \\
\text { forestales y } \\
\text { de interfase }\end{array}$ & 4100 & 111 & Comercio & $\begin{array}{l}\text { \$1.271.4 } \\
\text { millones- } \\
\text { Reconstrucción } \\
\text { USD \$1.54 } \\
\text { millones }\end{array}$ \\
\hline $\begin{array}{l}\text { Barrio Cerro } \\
\text { El Litre, } 2014\end{array}$ & Valparaíso & Valparaíso & $\begin{array}{l}\text { Incendios } \\
\text { forestales y } \\
\text { de interfase }\end{array}$ & 1200 & 126 & $\begin{array}{l}\text { Servicios y } \\
\text { Comercio }\end{array}$ & $\begin{array}{l}\text { \$2.065.3 } \\
\text { millones- } \\
\text { Reconstrucción } \\
\text { USD \$2.51 } \\
\text { millones }\end{array}$ \\
\hline $\begin{array}{l}\text { Barrio Cerro } \\
\text { La Cruz, } 2014\end{array}$ & Valparaíso & Valparaíso & $\begin{array}{l}\text { Incendios } \\
\text { forestales y } \\
\text { de interfase }\end{array}$ & 3950 & 121 & Comercio & $\begin{array}{l}\text { \$1.921.0 } \\
\text { millones- } \\
\text { Reconstrucción } \\
\text { USD } \$ 0.8 \\
\text { millones }\end{array}$ \\
\hline $\begin{array}{l}\text { Barrio } \\
\text { Merced-La } \\
\text { Virgen, } 2014\end{array}$ & Valparaíso & Valparaíso & $\begin{array}{l}\text { Incendios } \\
\text { forestales y } \\
\text { de interfase }\end{array}$ & 1600 & 98 & Comercio & $\begin{array}{l}\text { \$1.969.4 } \\
\text { millones- } \\
\text { Reconstrucción } \\
\text { USD \$2.33 } \\
\text { millones }\end{array}$ \\
\hline $\begin{array}{l}\text { Barrio centro } \\
\text { histórico, } \\
2016\end{array}$ & Los Lagos & Maullín & $\begin{array}{l}\text { Terremoto y } \\
\text { tsunami }\end{array}$ & 1120 & 46 & Comercio & $\begin{array}{l}\text { \$941.5 millones } \\
\text { USD \$1.14 } \\
\text { millones }\end{array}$ \\
\hline
\end{tabular}


Cada uno de los siete barrios tiene una historia particular de desastre: 1) los barrios de la Región de Arica y Parinacota: Jorge Inostroza y Puerta Norte de la Región, están ubicados en la ciudad de Arica uno al lado del otro, realizándose la intervención del PQMB a raíz del terremoto del Norte Grande del 2014; 2) los barrios de Valparaíso: Las Cañas, Cerro El Litre, Cerro La Cruz, y Merced-La virgen, fueron severamente impactados por los incendios forestales y de interfase del 2014; y 3) el barrio de la Región de Los Lagos: Centro Histórico, localizado en Maullín, población azotada por el tsunami generado por el terremoto Valdivia de 1960.

De los siete barrios analizados, los cuatro ubicados en Valparaíso recibieron recursos adicionales procedentes de presupuestos diferentes al PQMB, destinados a procesos extensos de reconstrucción.

Intervenciones de regeneración urbana del $\mathrm{PQMB}$ que integran la reducción del riesgo

En los siete casos seleccionados, las obras físicas estuvieron asociadas a la construcción de zonas seguras y de rutas de evacuación, el desarrollo de planes comunitarios de gestión de riesgos y manejo de emergencias, instalaciones estratégicas de seguridad, mejoramiento de la accesibilidad, incorporación de elementos de seguridad en plazas y áreas comunes como iluminación, señalética y redes secas para el combate de incendios (Tabla 3). Todas estas acciones demuestran la factibilidad de integrar en los barrios del programa, comointervenciones de regeneración urbana, la gestión de riesgos y así contribuir tanto a la seguridad, la resiliencia y la sostenibilidad de los barrios intervenidos, como también al fortalecimiento del capital social (Mayunga, 2007; Patel y Gleason, 2018; Townshend, Awosoga, Kulig y Fan, 2015).

Las obras o intervenciones físicas tradicionales del PQMB (sin gestión de riesgos) contemplan las categorías y tipos listados en la Tabla 3 (ver las dos primeras columnas). En el caso de las obras físicas llevadas a cabo en los siete barrios (Tabla 3, tercera columna), además de realizar las mejoras que tradicionalmente se hacen en estos espacios públicos, se incluyeron medidas de gestión de riesgos. Se puede decir entonces que, sin excepción, tanto los barrios sin reducción de riesgos como aquellos que lo integran, aportan al mejoramiento del entorno urbano y al bienestar de la comunidad; sin embargo, los barrios que incorporan gestión de riesgos, además de impactar positivamente en la calidad de vida del barrio, contribuyen decisivamente a su seguridad. Es altamente significativo señalar que la metodología "integral" del PQMB se convirtió en un vehículo para la incorporación de la reducción de riesgos, sin haber sido diseñada inicialmente para este propósito. 
TABLA 3. INTERVENCIONES FÍSICAS Y SOCIALES DEL PQMB EN LOS SIETE CASOS DE ESTUDIO

\section{Categorías de intervenciones físicas Siete casos de estudio - Barrios PQMB}

/ obras - PQMB

\begin{tabular}{|c|c|c|c|c|c|c|c|c|c|}
\hline 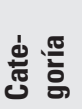 & Tipo & $\begin{array}{l}\text { Medida de reduc- } \\
\text { ción de riesgo de } \\
\text { desastre (RRD) }\end{array}$ & $\begin{array}{l}\text { Barrio } \\
\text { Jorge } \\
\text { Inostroza }\end{array}$ & $\begin{array}{l}\text { Barrio } \\
\text { Puerta } \\
\text { Norte }\end{array}$ & $\begin{array}{l}\text { Barrio Las } \\
\text { Cañas }\end{array}$ & $\begin{array}{l}\text { Barrio } \\
\text { Cerro El } \\
\text { Litre }\end{array}$ & $\begin{array}{l}\text { Barrio } \\
\text { Cerro La } \\
\text { Cruz }\end{array}$ & $\begin{array}{l}\text { Barrio } \\
\text { Merced- } \\
\text { La Virgen }\end{array}$ & $\begin{array}{l}\text { Barrio } \\
\text { Centro } \\
\text { Histórico }\end{array}$ \\
\hline \multirow{4}{*}{ 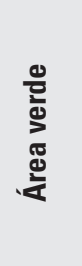 } & Parque & Zona segura & & & & & & $x$ & \\
\hline & Plaza & $\begin{array}{l}\text { Zona segura y } \\
\text { mitigación }\end{array}$ & & & $X$ & $X$ & $X$ & $X$ & \\
\hline & Platabanda & Mitigación & & & & & & & \\
\hline & Mirador & $\begin{array}{l}\text { Zona segura y } \\
\text { mitigación }\end{array}$ & & & $X$ & $X$ & & $X$ & $X$ \\
\hline \multirow{2}{*}{ 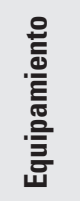 } & Social & $\begin{array}{l}\text { Apoyo habitabili- } \\
\text { dad zona segura / } \\
\text { formación }\end{array}$ & & & $X$ & $X$ & $X$ & $X$ & \\
\hline & Deportivo & Zona segura & & & $x$ & $x$ & $x$ & $x$ & \\
\hline \multirow{5}{*}{ 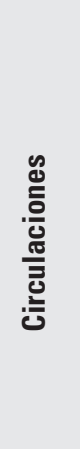 } & Calles & $\begin{array}{l}\text { Vías de } \\
\text { evacuación }\end{array}$ & & & $X$ & $X$ & $X$ & $X$ & $X$ \\
\hline & Pasajes & $\begin{array}{l}\text { Vías de } \\
\text { evacuación y } \\
\text { mitigación }\end{array}$ & & & $X$ & $X$ & $X$ & $X$ & \\
\hline & $\begin{array}{l}\text { Escaleras / } \\
\text { red seca }\end{array}$ & $\begin{array}{l}\text { Vías de } \\
\text { evacuación y } \\
\text { mitigación }\end{array}$ & & & $X$ & $X$ & $X$ & $X$ & \\
\hline & Ciclovías & Mitigación & & & & & $X$ & & \\
\hline & $\begin{array}{l}\text { Calles peato- } \\
\text { nales }\end{array}$ & $\begin{array}{l}\text { Vías evacuación } \\
\text { y mitigación }\end{array}$ & & & $X$ & $X$ & $X$ & $X$ & \\
\hline \multirow{3}{*}{ 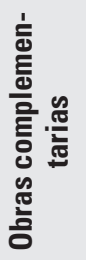 } & $\begin{array}{l}\text { Colectores } \\
\text { agua Iluvia }\end{array}$ & Mitigación & & & $x$ & $x$ & $X$ & $x$ & \\
\hline & $\begin{array}{l}\text { Muros de } \\
\text { contención }\end{array}$ & Mitigación & & & $X$ & $X$ & $X$ & $X$ & \\
\hline & $\begin{array}{l}\text { Saneamiento } \\
\text { aguas ser- } \\
\text { vidas }\end{array}$ & Mitigación & & & $X$ & $X$ & $x$ & $x$ & \\
\hline
\end{tabular}




\begin{tabular}{|c|c|c|c|c|c|c|c|c|c|}
\hline \multicolumn{3}{|c|}{$\begin{array}{l}\text { Categorías de intervenciones físicas } \\
\text { / obras - PQMB }\end{array}$} & \multicolumn{4}{|c|}{ Siete casos de estudio - Barrios PQMB } & \multirow[b]{2}{*}{$\begin{array}{l}\text { Barrio } \\
\text { Cerro La } \\
\text { Cruz }\end{array}$} & \multirow[b]{2}{*}{$\begin{array}{l}\text { Barrio } \\
\text { Merced- } \\
\text { La Virgen }\end{array}$} & \multirow[b]{2}{*}{$\begin{array}{l}\text { Barrio } \\
\text { Centro } \\
\text { Histórico }\end{array}$} \\
\hline 爮 䒿 & Tipo & $\begin{array}{l}\text { Medida de reduc- } \\
\text { ción de riesgo de } \\
\text { desastre (RRD) }\end{array}$ & $\begin{array}{l}\text { Barrio } \\
\text { Jorge } \\
\text { Inostroza }\end{array}$ & $\begin{array}{l}\text { Barrio } \\
\text { Puerta } \\
\text { Norte }\end{array}$ & $\begin{array}{l}\text { Barrio Las } \\
\text { Cañas }\end{array}$ & $\begin{array}{l}\text { Barrio } \\
\text { Cerro El } \\
\text { Litre }\end{array}$ & & & \\
\hline \multirow{3}{*}{ 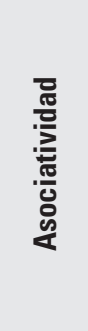 } & \multirow{2}{*}{ 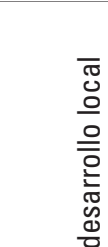 } & $\begin{array}{l}\text { Implementación } \\
\text { de alertas tem- } \\
\text { pranas }\end{array}$ & $X$ & $x$ & $x$ & $X$ & $X$ & $X$ & $X$ \\
\hline & & $\begin{array}{l}\text { Plan de res- } \\
\text { puesta a de- } \\
\text { sastre }\end{array}$ & $X$ & $X$ & $X$ & $X$ & $X$ & $X$ & $X$ \\
\hline & 可 & $\begin{array}{l}\text { Brigada de } \\
\text { emergencia }\end{array}$ & $X$ & $X$ & $X$ & $X$ & $X$ & $X$ & $X$ \\
\hline \multirow{2}{*}{ 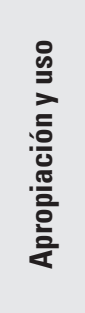 } & $\begin{array}{l}\overline{0} \\
\frac{0}{U} \\
0 \\
\text { : } \\
: \frac{0}{u}\end{array}$ & $\begin{array}{l}\text { Manual/uso } \\
\text { mantención y } \\
\text { apropiación de } \\
\text { zona segura }\end{array}$ & & & $X$ & $X$ & $X$ & $X$ & $X$ \\
\hline & 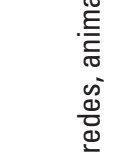 & $\begin{array}{l}\text { Diseños partici- } \\
\text { pativos de vías } \\
\text { de evacuación } \\
\text { y zonas seguras }\end{array}$ & $X$ & $x$ & $X$ & $x$ & $x$ & $X$ & $x$ \\
\hline \multirow{3}{*}{ 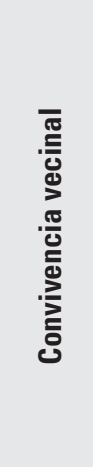 } & 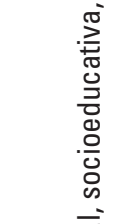 & $\begin{array}{l}\text { Curso de ONE- } \\
\text { MI para con- } \\
\text { formar equipos } \\
\text { comunitarios } \\
\text { de respuesta a } \\
\text { emergencias }\end{array}$ & $X$ & $X$ & $X$ & $X$ & $X$ & $X$ & $X$ \\
\hline & 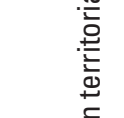 & $\begin{array}{l}\text { Curso comu- } \\
\text { nitario familia } \\
\text { preparada }\end{array}$ & $X$ & $X$ & $X$ & $X$ & $x$ & $x$ & $X$ \\
\hline & 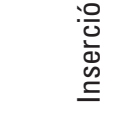 & $\begin{array}{l}\text { Curso micro- } \\
\text { zonificación } \\
\text { amenazas }\end{array}$ & & & & & & & \\
\hline
\end{tabular}


El PQMB, a través de una regulación interna del 2007, desarrolló un manual de procedimientos de forma de integrar su objetivo de

\begin{abstract}
"contribuir al mejoramiento de la calidad de vida de los habitantes de barrios que presentan problemas de deterioro urbano y habitacional, segregación y vulnerabilidad social, y exposición a riesgos o desastres, a través del mejoramiento y/o dotación de espacios públicos, equipamiento comunitario y entornos barriales y del fortalecimiento de la participación de vecinos" (MINVU, s.f., p. 3).
\end{abstract}

Como se puede ver en la Figura 2, el PQMB ha definido un modelo operativo que contempla tres fases de intervención (y que puede durar entre tres y cuatro años dependiendo del barrio) las que han sido adaptadas con el objetivo de incorporar la perspectiva del riesgo. En la fase I, contemplada para el diagnóstico del barrio, son consideradas una serie de herramientas, como encuestas, recorridos barriales y cartografía participativa, las que han sido adaptadas con el objetivo de incorporar la perspectiva del riesgo. En lo que respecta a la fase II, a través de la gestión de riesgos se llevan a cabo las obras de mitigación y mejoramiento de la seguridad en espacios públicos, así como los talleres de seguridad al interior de la vivienda. Se contemplan también las intervenciones sociales con talleres de formación según tipo de amenaza y la definición de mecanismos de coordinación multisectorial. En la fase III, de evaluación de la estrategia transversal de gestión del riesgo, se llevan a cabo las encuestas de verificación de resultados, la construcción de la memoria histórica del barrio, y la definición de compromisos. Si aproximamos dichas fases a la gestión del riesgo, estas prevén tres fases: 1) Identificación del riesgo, 2) Reducción del riesgo y manejo del desastre, y 3) Evaluación de la estrategia transversal de gestión del riesgo.

En consistencia con el método de análisis comparativo de estudios de caso y la hipótesis propuesta, se incluye a continuación la Tabla 4 que resume los resultados obtenidos de la evaluación de la estrategia transversal de gestión del riesgo para cada uno de los barrios.

La Tabla 4 muestra como en esta Fase I de la evaluación hay consistencia en los siete casos en cuanto al cumplimiento de tres actividades esenciales: la revisión de los instrumentos de planificación, el taller de RRD, y el recorrido barrial para la RRD. Con excepción de un solo caso, en todos se conformaron los comités de operativos de emergencia; en cinco de los siete casos se incorporó un capítulo de RRD en el plan maestro del barrio y se desarrollaron perfiles de proyecto de RRD dentro del plan maestro.

Destacan en esta tabla los barrios de la comuna de Arica, los cuales no incorporaron un capítulo de RRD en el plan maestro del proyecto ni desarrollaron perfiles de proyecto de RRD dentro de éste. Es importante indicar aquí, que la inclusión del tema de RRD se basaba en una sugerencia técnica, pero se carecía de un 


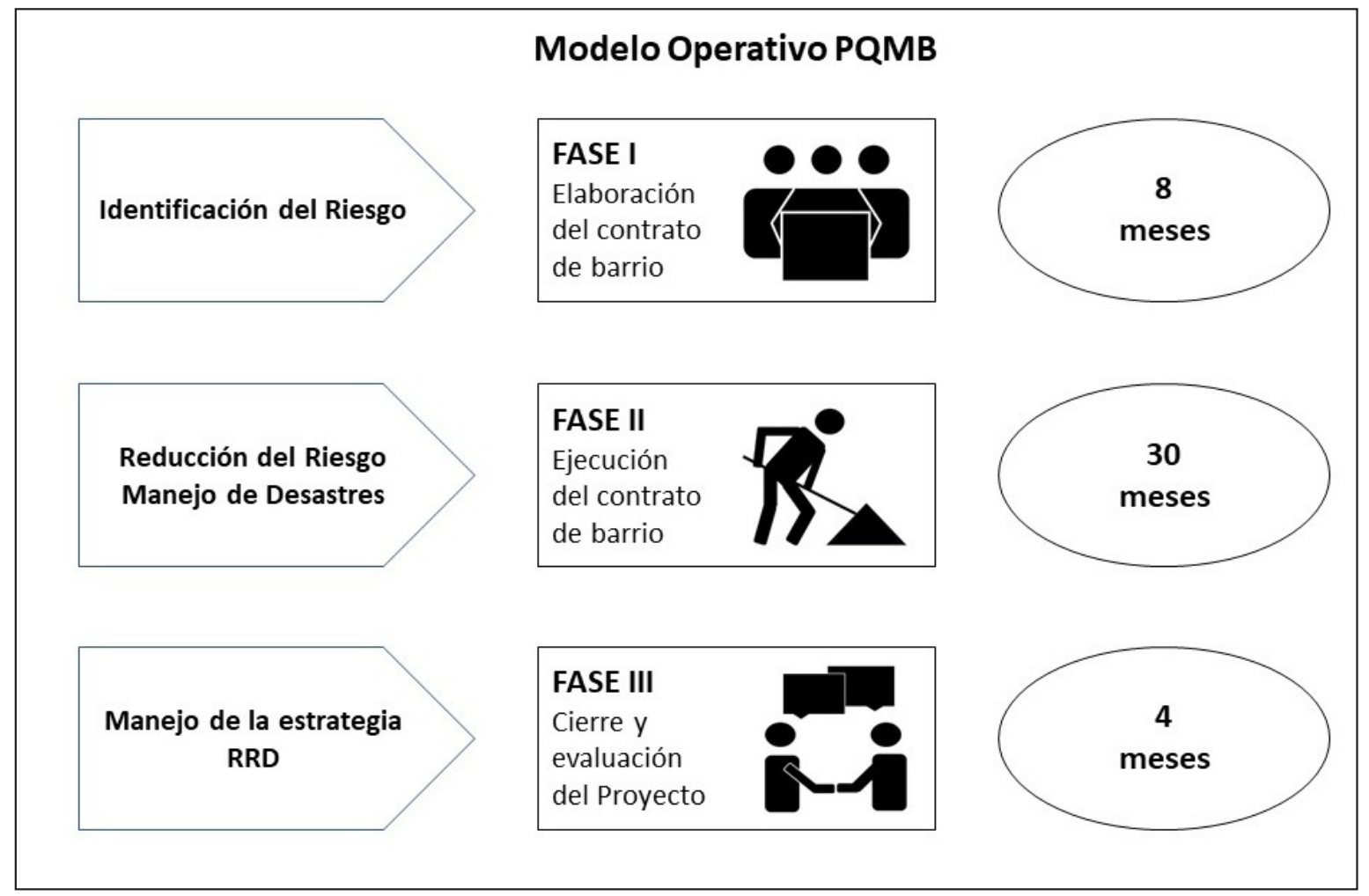

Fuente: Elaboración a partir del modelo MINVU

instrumento legal que obligara su aplicación, por lo que su adopción quedaba a criterio de las autoridades.

Se debe resaltar que el barrio de Maullín (centro histórico, 2016) fue el único que avanzó en la primera fase en la cartografía participativa y en los mapas técnicos, como instrumentos que identifican con detalle los lugares con mayor exposición a amenazas en la primera fase; esto le significó ser el único barrio en llegar a la calificación de óptimo desempeño en esta Fase I de la evaluación. 
TABLA 4. EVALUACIÓN FASE I: IDENTIFICACIÓN DEL RIESGO PARA CADA CASO DE ESTUDIO DEL PQMB

\begin{tabular}{|c|c|c|c|c|c|c|c|}
\hline Barrio & $\begin{array}{l}\text { Barrio Jorge } \\
\text { Inostroza }\end{array}$ & $\begin{array}{l}\text { Barrio } \\
\text { Puerta } \\
\text { Norte }\end{array}$ & $\begin{array}{c}\text { Barrio Las } \\
\text { Cañas }\end{array}$ & $\begin{array}{l}\text { Barrio } \\
\text { Cerro El } \\
\text { Litre }\end{array}$ & $\begin{array}{l}\text { Barrio } \\
\text { Cerro La } \\
\text { Cruz }\end{array}$ & $\begin{array}{l}\text { Barrio } \\
\text { Merced- La } \\
\text { Virgen }\end{array}$ & $\begin{array}{l}\text { Barrio } \\
\text { Centro } \\
\text { Histórico }\end{array}$ \\
\hline $\begin{array}{l}\text { Revisión de instrumentos } \\
\text { de planificación } \\
\text { territorial y estudios de } \\
\text { riesgos }\end{array}$ & 1 & 1 & 1 & 1 & 1 & 1 & 1 \\
\hline $\begin{array}{l}\text { Aplicación encuesta } \\
\text { de caracterización, } \\
\text { percepción y con } \\
\text { preguntas de RRD }\end{array}$ & $0 *$ & $0^{*}$ & 0 & 0 & 0 & 0 & 1 \\
\hline $\begin{array}{l}\text { Taller de introducción a } \\
\text { la RRD. }\end{array}$ & 1 & 1 & 1 & 1 & 1 & 1 & 1 \\
\hline Recorrido barrial. & 1 & 1 & 1 & 1 & 1 & 1 & 1 \\
\hline $\begin{array}{l}\text { Cartografía participativa } \\
\text { de riesgo de desastres. }\end{array}$ & 0 & 0 & 0 & 0 & 0 & 0 & 1 \\
\hline $\begin{array}{l}\text { Mapa técnico de riesgo } \\
\text { de desastres. }\end{array}$ & 0 & 0 & 0 & 0 & 0 & 0 & 1 \\
\hline $\begin{array}{l}\text { Conformación COE } \\
\text { Barrial. }\end{array}$ & 1 & 1 & 1 & 1 & 1 & 1 & 0 \\
\hline $\begin{array}{l}\text { Incorporación de } \\
\text { capítulo sobre RRD en } \\
\text { diagnóstico compartido. }\end{array}$ & 0 & 0 & 1 & 1 & 1 & 1 & 1 \\
\hline $\begin{array}{l}\text { Desarrollo de perfiles de } \\
\text { proyectos de RRD en el } \\
\text { Plan Maestro. }\end{array}$ & 0 & 0 & 1 & 1 & 1 & 1 & 1 \\
\hline $\begin{array}{l}\text { Deficiente: 0-3; } \\
\text { Aceptable: 4-6; Óptimo: } \\
\text { 7-9 }\end{array}$ & $\begin{array}{c}4 \\
\text { Aceptable }\end{array}$ & $\begin{array}{c}4 \\
\text { Aceptable }\end{array}$ & $\begin{array}{c}6 \\
\text { Aceptable }\end{array}$ & $\begin{array}{c}6 \\
\text { Aceptable }\end{array}$ & $\begin{array}{c}6 \\
\text { Aceptable }\end{array}$ & $\begin{array}{c}6 \\
\text { Aceptable }\end{array}$ & $\begin{array}{c}8 \\
\text { Óptimo }\end{array}$ \\
\hline
\end{tabular}

*Se aplicó encuesta sin preguntas RRD;

Deficiente: hay información y conocimientos incompletos en la identificación y evaluación del riesgo de desastres en el barrio. Aceptable: las actividades para identificar y evaluar el riesgo de desastres han entregado un conocimiento parcial de las amenazas, vulnerabilidades y capacidades dentro del barrio.

Óptima: las estrategias de identificación y evaluación del riesgo de desastres en el barrio han sido efectivas y se ha logrado un conocimiento generalizado en la población de las amenazas, vulnerabilidades y capacidades. 
La Tabla 5-A (mitad superior), hace referencia a la evaluación del componente de reducción de riesgos de la Fase II (donde se llevan a cabo la implementación de las obras físicas, las vías de evacuación y las áreas de seguridad), evaluación que muestra una varianza significativa en los siete casos de estudio. Se destaca la consistencia de los cuatro barrios de Valparaíso (Las Cañas, Cerro El Litre, Cerro La Cruz, Merced-La Virgen) con un desempeño óptimo, así como el avance de seis de los siete barrios en el incremento de la seguridad en la vivienda. Llama la atención las deficiencias de los dos proyectos para barrios de la comuna de Arica, donde aun cuando hay una alta exposición a la amenaza de tsunami, no se desarrollaron obras de mitigación, ni de mejoramiento de la seguridad en espacios públicos, ni de implementación de zonas de seguridad y vías de evacuación. Es importante indicar para estos casos que las vías de evacuación ya existían y solo se requería construir las zonas seguras que debían ubicarse pasando la línea del ferrocarril que atraviesa todo Arica. Este hecho constituyó una barrera imposible de resolver en los tiempos del programa. Al momento de escribir este artículo, hay un acuerdo pendiente con la empresa ferroviaria para hacer un paso expedito, con una barrera automática en caso de evacuación.

La evaluación del componente de manejo de desastres de la Fase II (Tabla 5-B, mitad inferior), muestra la mayor consistencia y regularidad con un desempeño óptimo en todos los siete casos de estudio. Este es un gran logro del PQMB, donde los vecinos, las autoridades del municipio y las organizaciones de protección civil convergen para acordar un plan de gestión del riesgo y manejo de emergencias, con roles y responsabilidades.

La Tabla 6 muestra los resultados de la evaluación de la fase, considerando la estrategia transversal de gestión de riesgos al culminar cada barrio. Se observan claramente tres tendencias: 1) La falta de un compromiso (en algunos casos escrito) por parte de los municipios para la continuidad de la RRD en su futura agenda de desarrollo; 2) la deficiencia de los dos barrios de Arica para adoptar la estrategia transversal de gestión de riesgos; y 3 ) el alto compromiso de los cuatro barrios para Valparaíso (Las Cañas, Cerro El Litre, Cerro La Cruz, Merced-La Virgen) y Maullín (Centro Histórico) para adoptar la estrategia transversal de gestión de riesgos.

Queda en evidencia el excelente desempeño de los cuatro barrios de la comuna de Valparaíso, seguidos del barrio de la comuna de Maullín (barrio centro histórico), al igual que los aspectos por mejorar de los dos barrios de la comuna de Arica. De esta forma, se confirma la hipótesis propuesta para este estudio: Los procesos de intervención social y física de regeneración urbana del $P Q M B$ que cuentan con un enfoque transversal de gestión de riesgos están en 
TABLA 5. EVALUACIÓN FASE II: COMPONENTES DE REDUCCIÓN DEL RIESGO Y MANEJO DEL DESASTRE

\begin{tabular}{|c|c|c|c|c|c|c|c|}
\hline Barrio & $\begin{array}{l}\text { Barrio Jorge } \\
\text { Inostroza }\end{array}$ & $\begin{array}{l}\text { Barrio } \\
\text { Puerta } \\
\text { Norte }\end{array}$ & $\begin{array}{l}\text { Barrio } \\
\text { Las } \\
\text { Cañas }\end{array}$ & $\begin{array}{l}\text { Barrio } \\
\text { Cerro El } \\
\text { Litre }\end{array}$ & $\begin{array}{l}\text { Barrio } \\
\text { Cerro La } \\
\text { Cruz }\end{array}$ & $\begin{array}{l}\text { Barrio } \\
\text { Merced- } \\
\text { La Virgen }\end{array}$ & $\begin{array}{l}\text { Barrio Centro } \\
\text { Histórico }\end{array}$ \\
\hline $\begin{array}{l}\text { 1. Desarrollo de obras de } \\
\text { mitigación y mejoramiento de la } \\
\text { seguridad en espacios públicos. }\end{array}$ & 0 & 0 & 1 & 1 & 1 & 1 & 1 \\
\hline $\begin{array}{l}\text { 2. implementación de zonas de } \\
\text { seguridad y vías de evacuación. }\end{array}$ & 0 & 0 & 1 & 1 & 1 & 1 & 1 \\
\hline $\begin{array}{l}\text { 3. Desarrollo de talleres de } \\
\text { seguridad al interior de la } \\
\text { vivienda. }\end{array}$ & 1 & 1 & 1 & 1 & 1 & 1 & 0 \\
\hline $\begin{array}{l}\text { Deficiente: 0-1; Aceptable: 2; } \\
\text { Óptimo: } 3\end{array}$ & $\begin{array}{c}1 \\
\text { Deficiente }\end{array}$ & $\begin{array}{c}1 \\
\text { Deficiente }\end{array}$ & $\begin{array}{c}3 \\
\text { Óptimo }\end{array}$ & $\begin{array}{c}3 \\
\text { Óptimo }\end{array}$ & $\begin{array}{c}3 \\
\text { Óptimo }\end{array}$ & $\begin{array}{c}3 \\
\text { Óptimo }\end{array}$ & $\begin{array}{c}2 \\
\text { Aceptable }\end{array}$ \\
\hline
\end{tabular}

Deficiente: el barrio cuenta con un avance insuficiente en las obras de reducción del riesgo necesarias o en el entrenamiento en seguridad.

Aceptable: el barrio no cuenta con todas las obras de reducción del riesgo necesarias y/o no hay avances en el entrenamiento en seguridad

Óptimo: el barrio cuenta con obras de mitigación, seguridad y señalética apropiada para la evacuación y conocimiento de las zonas seguras, así como en o en el entrenamiento en seguridad.

\section{B. Componente de manejo del desastre - Plan de gestión social para cada caso de estudio del POMB}

\begin{tabular}{|c|c|c|c|c|c|c|c|}
\hline Barrio & $\begin{array}{l}\text { Barrio Jorge } \\
\text { Inostroza }\end{array}$ & $\begin{array}{l}\text { Barrio } \\
\text { Puerta } \\
\text { Norte }\end{array}$ & $\begin{array}{l}\text { Barrio Las } \\
\text { Cañas }\end{array}$ & $\begin{array}{l}\text { Barrio } \\
\text { Cerro El } \\
\text { Litre }\end{array}$ & $\begin{array}{c}\text { Barrio } \\
\text { Cerro La } \\
\text { Cruz }\end{array}$ & $\begin{array}{c}\text { Barrio } \\
\text { Merced- } \\
\text { La Virgen }\end{array}$ & $\begin{array}{l}\text { Barrio Centro } \\
\text { Histórico }\end{array}$ \\
\hline $\begin{array}{l}\text { 1. Desarrollo de talleres por tipo de } \\
\text { amenaza }\end{array}$ & 1 & 1 & 1 & 1 & 1 & 1 & 1 \\
\hline $\begin{array}{l}\text { 2. Coordinación multisectorial } \\
\text { para la preparación, respuesta y } \\
\text { recuperación. }\end{array}$ & 1 & 1 & 1 & 1 & 1 & 1 & 1 \\
\hline Deficiente: 0; Aceptable: 1; Óptimo: 2 & $\begin{array}{c}2 \\
\text { Óptimo }\end{array}$ & $\begin{array}{c}2 \\
\text { Óptimo }\end{array}$ & $\begin{array}{c}2 \\
\text { Óptimo }\end{array}$ & $\begin{array}{c}2 \\
\text { Óptimo }\end{array}$ & $\begin{array}{c}2 \\
\text { Óptimo }\end{array}$ & $\begin{array}{c}2 \\
\text { Óptimo }\end{array}$ & $\begin{array}{c}2 \\
\text { Óptimo }\end{array}$ \\
\hline
\end{tabular}

Deficiente: existe una importante falta de coordinación para la reducción del riesgo y preparación frente a emergencias.

Aceptable: existe una incipiente organización a nivel del barrio -entre vecinos y organizaciones de protección civil y el municipiopara la coordinación en reducción del riesgo y preparación a emergencias. Sin embargo, falta fortalecer las capacidades comunitarias para una eficiente respuesta los desastres.

Óptimo: se ha logrado coordinar a los vecinos, el municipio y las organizaciones de protección civil para elaborar un plan de reducción del riesgo y de preparación con roles asignados en casos de emergencia. 
mejores condiciones para enfrentar problemas de exposición a riesgos socionaturales y para adelantar procesos de recuperación pos-evento; no obstante, se reconoce que las diferentes intervenciones no logran el mismo impacto esperado.

Sin embargo, la verdadera prueba de la hipótesis se dará cuando las comunidades de estos barrios deban responder al tipo de evento socionatural para el cual se diseñaron e implementaron las intervenciones físicas y sociales (terremoto y tsunami, incendios forestales y de interfase).

En cuanto al método empleado, podemos indicar que las cinco preguntas de Krehl y Weck (2019), permiten que estas investigaciones sean más transparentes y específicas, contribuyendo a la solidez de las conclusiones desde una perspectiva académica y práctica.

Los autores reconocen que hay limitaciones en el estudio: la relativa reciente adopción de la política de reducción de riesgos en el PMQB; el número reducido de barrios que han incorporado esta aproximación y el aún menor número de barrios con este enfoque que han culminado. Es importante profundizar en estudios que permitan esclarecer los factores asociados a las diferencias observadas en los diferentes casos de estudio, los cuales deberán considerar no solo los aspectos físicos de los barrios estudiados y su equipamiento urbano, sino también las características demográficas, geográficas, políticas, socioculturales y económicas (llegando a temas de mayor granulación, desdelas políticasy procedimientos técnicos empleados por el PQMB para abordar la temática de gestión de riesgos, hasta la composición y capacidades de los miembros de los equipos de trabajo del PQMB, del municipio y de las comunidades involucradas).

\section{Conclusiones}

El PQMB como política pública de regeneración urbana, constituye un tipo de gestión territorial articulado bajo un modelo de intervención donde interactúan los diferentes niveles territoriales y la ciudadanía mediante un modelo de urbanismo ciudadano caracterizado por la coproducción participativa a lo largo de todo el proceso de diagnóstico, diseño y ejecución de proyectos físico-sociales, estableciendo acuerdos de convivencia entre las partes.

El estudio confirma que la incorporación transversal de medidas de reducción de riesgo en los diseños -tanto en las líneas de obras de infraestructura como en las obras sociales- de mejoramiento urbano del PQMB contribuyen efectiva y eficientemente al mejoramiento de la seguridad del barrio y su comunidad, a la vez que fortalecen la participación ciudadana, el conocimiento del territorio, el incremento de las áreas verdes y espacios comunes, el mejoramiento de la conectividad y otras acciones que aportan finalmente a la resiliencia sustentable de la comunidad ante desastres. 
TABLA 6. EVALUACIÓN DE LA FASE III: ESTRATEGIA TRANSVERSAL DE GESTIÓN DE RIESGOS PARA CADA CASO DE ESTUDIO DEL PQMB

\begin{tabular}{|c|c|c|c|c|c|c|c|}
\hline Barrio & $\begin{array}{c}\text { Barrio } \\
\text { Jorge } \\
\text { Inostroza }\end{array}$ & $\begin{array}{c}\text { Barrio } \\
\text { Puerta } \\
\text { Norte }\end{array}$ & $\begin{array}{c}\text { Barrio Las } \\
\text { Cañas }\end{array}$ & $\begin{array}{c}\text { Barrio } \\
\text { Cerro El } \\
\text { Litre }\end{array}$ & $\begin{array}{c}\text { Barrio } \\
\text { Cerro La } \\
\text { Cruz }\end{array}$ & $\begin{array}{l}\text { Barrio } \\
\text { Merced- } \\
\text { La Virgen }\end{array}$ & $\begin{array}{c}\text { Barrio } \\
\text { Centro } \\
\text { Histórico }\end{array}$ \\
\hline $\begin{array}{l}\text { 1. Aplicación } \\
\text { de encuesta de } \\
\text { verificación de } \\
\text { resultados. }\end{array}$ & $0 *$ & $0^{*}$ & 1 & 1 & 1 & 1 & 1 \\
\hline $\begin{array}{l}\text { 2. Incorporación } \\
\text { de capítulo de } \\
\text { memoria histórica } \\
\text { en “Historia de } \\
\text { Barrio". }\end{array}$ & 0 & 0 & 1 & 1 & 1 & 1 & 1 \\
\hline
\end{tabular}

\begin{tabular}{|c|c|c|c|c|c|c|c|}
\hline $\begin{array}{l}\text { 3. Incorporación de } \\
\text { capítulo de RRD en } \\
\text { el informe final }\end{array}$ & 0 & 0 & 1 & 1 & 1 & 1 & 1 \\
\hline $\begin{array}{l}\text { 4. Existencia de } \\
\text { un compromiso } \\
\text { municipal de } \\
\text { continuidad de la } \\
\text { RRD en Agenda } \\
\text { futura. }\end{array}$ & 0 & 0 & $0^{* *}$ & $0^{* *}$ & $0^{* *}$ & $0^{* *}$ & 0 \\
\hline
\end{tabular}

$\begin{array}{lccccccc}\text { Deficiente: } 0-1 ; & 0 & 0 & 3 & 3 & 3 & 3 & 3 \\ \text { Aceptable: 2-3; } & \text { Deficiente } & \text { Deficiente } & \text { Aceptable } & \text { Aceptable } & \text { Aceptable } & \text { Aceptable } & \text { Aceptable } \\ \text { Óptimo: } 4 & & & \end{array}$

* Encuesta sin RRD

** No quedaron escritos los compromisos

Deficiente: no se aplicó la evaluación del programa o no se hicieron los informes sobre la estrategia de RRD del programa. Aceptable: la evaluación y difusión de la Estrategia de RRD del programa se realizó, pero necesita ser fortalecida. Optima: los informes sobre las estrategias de reducción del riesgo del programa han sido efectivos y se ha logrado contribuir a la RRD en el barrio. 
El valor del presente estudio consiste en ofrecer un cuidadoso análisis de los resultados obtenidos en experiencias específicas y escenarios únicos, que permite establecer comparaciones con casos similares de regeneración urbana y gestión del riesgo, así como reflexionar sobre los procesos empleados y los resultados obtenidos, logrando informar decisiones futuras tanto en la línea de investigación como en la práctica de la gestión urbana.

El MINVU, a través del PQMB, demuestra un claro compromiso y un avance indiscutible como política pública de regeneración urbana, llegando a incorporar, con la colaboración de universidades nacionales e internacionales, el tema de la gestión de riesgos y manejo de desastres en forma transversal, constituyéndose en un modelo de gestión para los otros ministerios de vivienda y urbanismo de la región Latinoamericana que enfrentan realidades y retos similares.

\section{Referencias bibliográficas}

Bewick, C.-A., y Tsenkova, S. (2002). Overview of urban regeneration polices. En S. Tsenkova (Ed.), Urban regeneration: Learning from the British experience. Calgary, Alberta: Faculty of Environmental Design, University of Calgary.

Couch, C. (1990). Urban renewal: theory and practice. London: Macmillan Education.

Couch, C. (1999). Housing development in the city centre. Planning Practice and Research, 14(1), 69-86. https://doi.org/10.1080/02697459915832
Goodrick, D. (2014). Comparative case studies. Florence, Italy: UNICEF. Recuperado de https://www.unicef-irc.org/publications/754-comparative-case-studies-methodological-briefs-impact-evaluation-no-9.html

Güzey, 0̈. (2016). The last round in restructuring the city: Urban regeneration becomes a state policy of disaster prevention in Turkey. Cities, 50, 40-53.

https://doi.org/10.1016/j.cities.2015.08.010

Hart, G. (2018). Relational comparison revisited: Marxist postcolonial geographies in practice. Progress in Human Geography, 42(3), 371-94. https://doi.org/10.1177/0309132516681388

Informe del grupo de trabajo intergubernamental de expertos de composición abierta sobre los indicadores y la terminología relacionados con la reducción del riesgo de desastres. (2016). Naciones Unidas. Recuperado de http://www.preventionweb.net/files/50683 oiewgreportspanish.pdf

Krehl, A., y Weck, S. (2019). Doing comparative case study research in urban and regional studies: What can be learnt from practice? European Planning Studies, 28(9), 1858-1876. https://doi.org/10.1080/09654313.2019.1699909

Mayer, M. (2007). Contesting the neoliberalization of urban governance. En H. Leitner, P. Jamie y S. Eric. (Eds.), Contesting neoliberalism: urban frontiers (pp. 90-115). London, Guilford Press.

Mayer, M. (2009). The 'right to the city' in the context of shifting mottos of urban social movements. City, 13(2-3), 362-374. https://doi.org/10.1080/13604810902982755 
Mayunga, J. (2007). Understanding and applying the concept of community disaster resilience: a capital-based approach. En Summer Academy for Social Vulnerability and Resilience Building, Munich, Germany.

Ministerio de Vivienda y Urbanismo. (s.f.). Manual de procedimientos programa de recuperación de barrios. MINVU. Recuperado de https:/www.minvu.cl/wp-content/uploads/2019/05/ Manual-de-Procedimiento-Programa-Recuperación-de-Barrios modif 04octll.pdf

Oficina Nacional de Emergencia del Ministerio del Interior. (2016). Plan estratégico nacional para la gestión del riesgo de desastres. ONEMI. Recuperado de

https://www.preventionweb.net/files/52889 52889planestrategicobaja.pdf

Patel, R. B. y Gleason, K. M. (2018). The association between social cohesion and community resilience in two urban slums of Port au Prince, Haiti. International Journal of Disaster Risk Reduction, 27, 161-167. https://doi.org/10.1016/j.ijdrr.2017.10.003

Presidencia Española. (2010). Reunión informal de ministros de desarrollo urbano: declaración. Toledo 22 de Junio de 2010. Comisión Europea. Recuperado de

https://ec.europa.eu/regional policy/archive/newsroom/ pdf/201006_toledo_declaration_es.pdf

Roberts, P. (2000). The evolution, definition and purpose of urban regeneration. En P. Roberts y H. Sykes, (Eds.), Urban regeneration: a handbook. Los Angeles: SAGE.
Robinson, J. (2016). Comparative urbanism: New geographies and cultures of theorizing the urban. International Journal of Urban and Regional Research, 40(1), 187-99. https://doi.org/10.1111/1468-2427.12273

Sarmiento, J. P., Castro-Correa, C. P., Sandoval, V., y Hoberman, G. (2020). Cohesión social como base del mejoramiento de la gobernanza en asentamientos informales. Investigaciones Geográficas, (59), 59-69.

Smith, M. K. (2011). Neighbourhoods and regeneration - theory, practice, issues. The Encyclopaedia of Informal Education. Recuperado de https://infed.org/mobi/neighbourhoods-and-regeneration-theory-practice-issues/

Townshend, I., Awosoga, 0., Kulig, J., y Fan, H. (2015). Social cohesion and resilience across communities that have experienced a disaster. Natural Hazards, 76(2), 913-938. https://doi.org/10.1007/s11069-014-1526-4

Tsenkova, S. (Ed.). (2002). Urban regeneration: learning from the British experience. Calgary, Alberta: Faculty of Environmental Design, University of Calgary. 


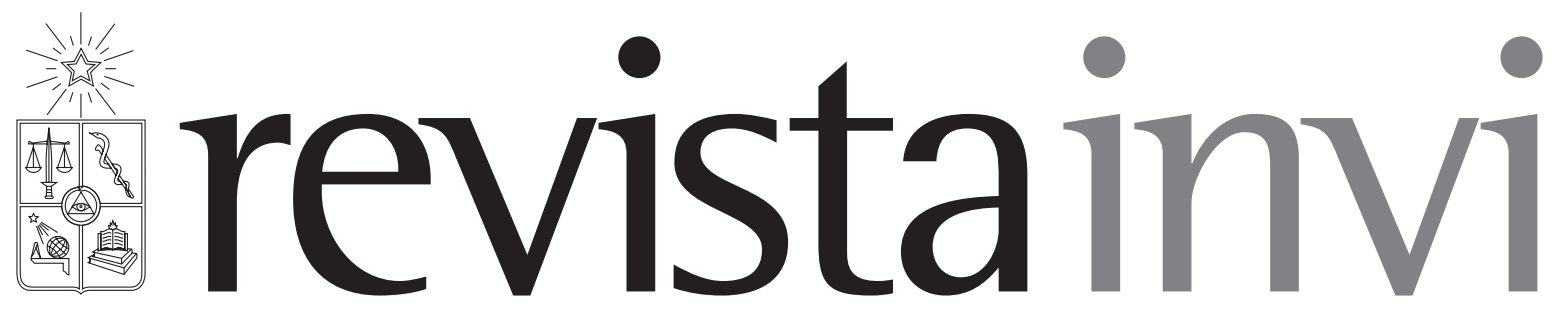

Revista INVI es una publicación periódica, editada por el Instituto de la Vivienda de la Facultad de Arquitectura y Urbanismo de la Universidad de Chile, creada en 1986 con el nombre de Boletín INVI. Es una revista académica con cobertura internacional que difunde los avances en el conocimiento sobre la vivienda, el hábitat residencial, los modos de vida y los estudios territoriales. Revista INVI publica contribuciones originales en español, inglés y portugués, privilegiando aquellas que proponen enfoques inter y multidisciplinares y que son resultado de investigaciones con financiamiento y patrocinio institucional. Se busca, con ello, contribuir al desarrollo del conocimiento científico sobre la vivienda, el hábitat y el territorio y aportar al debate público con publicaciones del más alto nivel académico.

Director: Dr. Ricardo Tapia Zarricueta, Universidad de Chile, Chile.

Editor: Dr. Luis Campos Medina, Universidad de Chile, Chile.

Editor asistente: Dr. Walter Imilan, Universidad de Chile, Chile.

Coeditora: Srta. Sandra Rivera, Universidad de Chile, Chile.

\section{COMITÉ EDITORIAL:}

Dr. Victor Delgadillo, Universidad Autónoma de la Ciudad de México, México.

Dra. María Mercedes Di Virgilio, CONICET/ IIGG, Universidad de Buenos Aires, Argentina.

Dra. Irene Molina, Uppsala Universitet, Suecia.

Dr. Gonzalo Lautaro Ojeda Ledesma, Universidad de Valparaíso, Chile.

Dra. Suzana Pasternak, Universidade de São Paulo, Brasil.

Dr. Javier Ruiz Sánchez, Universidad Politécnica de Madrid, España.

Dra. Elke Schlack Fuhrmann, Pontificia Universidad Católica de Chile, Chile.

Dr. Carlos Alberto Torres Tovar, Universidad Nacional de Colombia, Colombia.

Sitio web: http://www.revistainvi.uchile.cl/

Correo electrónico: revistainvi@uchilefau.cl

Licencia de este artículo: Creative Commons Atribución-Compartirlgual 4.0 Internacional (CC BY-SA 4.0) 